\title{
Systems engineering: a key for success in aerospace operations
}

\section{Commentary}

The term "systems engineering" when entered into the Google search page, produces a significant number of results, evidence that systems engineering is recognized as being important for the success of essentially all products. Since most readers of this item will be rather well versed in documents concerning systems engineering, I have elected to share some of the points made on this subject relative to aerospace operations in a document developed by the European Cooperation for Space Standardization (ECSS), a component of the European Space Agency. ${ }^{1}$ The ECSS document defines systems engineering as "an interdisciplinary approach governing the total technical effort to transform requirements into a system solution." These elements include hardware, software, firmware, human resources, information, techniques, facilities, services, and other support elements. The systems engineering process is intrinsically iterative across the whole life cycle of an aerospace project and is produced under the leadership of engineering talents with technical excellence attributes. Systems engineering is not an administrative focused or led function. Technical excellence is the key to successful systems engineering and, thus, successful aerospace operations.

An article that addressed new synergies between systems engineering and diminishing manufacturing sources and material shortages made two important points. ${ }^{2}$

a. Systems engineering principles and best practices should be applied to enhance reliability, availability, maintainability, and sustainability through the entire life of a program,

b. Managing major programs effectively requires sound systems engineering.

Accordingly, technical excellence and the associated "tall poles", Pay attention to details, Leave no stone unturned, and Be aggressivenot passive are integral to ensuring the applications of the principals and best practices of systems engineering to aerospace operations, as well as to other program operations, to achieve the intended goals. ${ }^{3}$ This article is based on "Technical Excellence: A Requirement for Good Engineering” (AIAA-2008-1120), prepared and presented
Volume 2 Issue I - 2018

\author{
William WVaughan \\ NASA Emeritus, George C Marshall Space Flight Center, USA
}

Correspondence: William WVaughan, NASA Emeritus, George C Marshall Space Flight Center, 320 Sparkman Drive, Huntsville,AL 35805, Tel 256-96I-7759, Email william.w.vaughan@nasa.gov

Received: November 03, 2017 | Published: February 16, 2018

by the author at the 47th American Institute of Aeronautics and Astronautics Aerospace Sciences Meeting, January 7-11, 2008, Reno, NV. Plus the article "Systems Engineering" an editorial by the author published in the April-June 2016 issue of the Journal of Aerospace Technology and Management.

\section{Acknowledgements}

None.

\section{Conflict of interest}

Author declares that there is no conflict of interest.

\section{References}

1. Anon. System Engineering General Requirements. European Cooperation for Space Standardization, ECSS-E-ST-10C. 2009.

2. Bracuto C, Melnikow A, Zelinski E. New synergies between systems engineering and DMSMS. Defense Standardization Program Journal. 2010:3-8.

3. Dannenberg, KK. Management Philosophies as Applied to Major NASA Programs. Patent Number: NASA-CR-141258, NASA Technical Report; $1974.96 \mathrm{p}$. 